\title{
Sobre um certo discurso de professores de língua portuguesa e suas implicações para o ensino
}

\author{
José Cezinaldo Rocha Bessa \\ Universidade Estadual Paulista Júlio de Mesquita Filho - UNESP/FCLar \\ Universidade do Estado do Rio Grande do Norte - Campus de Pau dos Ferros
}

\begin{abstract}
Resumo
Objetivo com este texto suscitar algumas reflexões sobre certos discursos relacionados a questões de linguagem expressos por professores de língua portuguesa e que colaboram com a propagação de ideias infundadas sobre o fenômeno linguístico. Tomando tais reflexões como ponto de partida, tento problematizar possíveis implicações desses discursos para o ensino de língua materna. As reflexões e problematizações que apresento apontam na direção de que uma compreensão do fenômeno linguístico em sintonia com os pressupostos das ciências da linguagem, da Sociolinguística à Análise do Discurso, não é só desejável, mas também uma obrigação por parte do professor de língua portuguesa, como condição de um ensino de língua portuguesa responsável e comprometido em oferecer ao alunado uma formação condizente com o real funcionamento da língua(gem), com o seu uso pelos falantes/escreventes nas diversas situações de comunicação.
\end{abstract}

Palavras-chave: professores, Português, língua, ensino, Sociolinguística e Análise do Discurso.

\begin{abstract}
The aim of this article is to raise some reflections on how certain kinds of discourses of Portuguese teachers, related to language questions, spread unfounded ideas about linguistic phenomena. With those ideas as a starting point, I question possible implications of those discourses for mother tongue teaching. The reflections presented in this work point to the need for a broad understanding about linguistic phenomena that is in agreement with theories in the science of language, from sociolinguistics to discourse analysis, as a fundamental condition to carry out Portuguese language teaching in a responsible and committed way. Teachers have an obligation to offer students a language education that is coherent with how language really works, so that students can use language well when they read and write in real situations where language is used as communication.
\end{abstract}

Key words: teachers, Portuguese, language, teaching, sociolinguistics, discourse analysis 
"Nesse mundo, Pedrinho, precisamos conhecer a linguagem das gentes simples e também a linguagem dos pedantes - se não os pedantes nos embrulham”. (Fala de Dona Benta na obra Peter Pan, de Monteiro Lobato).

Se, por um lado, para o estudioso da linguagem, é indiscutível a contribuição que a linguística brasileira tem dado não só para uma melhor compreensão dos fenômenos linguísticos, mas também para o ensino de línguas, em especial o ensino de língua portuguesa, por outro lado, é questionável como muitos profissionais do ensino nessa especialidade revelem ainda desconhecimento ou compreensões equivocadas sobre questões de linguagem. O preocupante é constatar que esses profissionais têm colaborado com a propagação de ideias infundadas sobre o fenômeno linguístico, e não só no espaço de sala de aula. Isso parece ser uma clara indicação de que aquilo que Faraco (2001) já dizia, há 13 anos, sobre o lugar da linguística nos discursos sobre a língua no Brasil, ainda permanece bastante atual. Eis o que o autor expressou: "a linguística não conseguiu ainda ultrapassar minimamente as paredes dos centros de pesquisa e se difundir socialmente de modo a fazer ressoar o seu discurso em contraposição aos outros discursos que dizem a língua no Brasil” (2001, p. 38).

Tentando problematizar essa questão, sem pretensão alguma de esgotá-la, meu propósito com este texto é suscitar algumas reflexões a respeito de certos discursos sobre questões de linguagem expressos por professores de português que se manisfestam para além do espaço de sala de aula, incluindo aí o mundo das redes sociais, e que têm contribuido para difundir comprensões distorcidas sobre o fenômeno linguístico. Tomando tais reflexões como ponto de partida, tento problematizar possíveis implicações desses discursos para o ensino de língua materna. Para tanto, estou concebendo discurso com a ideia de assumir um posicionamento, na esteira do pensamento do Círculo de Bakhtin, ainda que não seja meu interesse aqui desenvolver propriamente uma análise utilizando-me dos procedimentos teórico-metodológicos bakhtinianos. Em conformidade com a leitura de textos de Bakhtin (2003), entendo discurso, portanto, como posição axiológica, partindo da ideia de que todo enunciado suscita sempre uma atitude responsiva ativa dos sujeitos em interação comunicativa.

Quero destacar, de início, que a motivação para escrever este texto nasce justamente de uma provocação suscitada em uma rede social por um professor de línguas que, dirigindose a um indivíduo nascido no Brasil e falante da língua portuguesa falada nesse país, imputalhes dizeres do tipo: "você não sabe português". A rede social a que me refiro é o Facebook. É importante que se diga que o referido post foi curtido, compartilhado e comentado também por outros professores, alguns dos quais se manifestaram reiterando o dizer expresso, e, 
quando não, intensificando um debate com posições distorcidas sobre outras questões relativas ao fenômeno linguístico. Para se ter uma ideia dos discursos sobre língua(gem) que são disseminados nessa rede social, bastar observar páginas como "Odeio quem escreve fala/errado", destinada, segundo a descrição que nela consta, "Para quem já perdeu a paciência com quem gosta de escrever ou falar errado".

Com alguma frequência, tenho me deparado com discursos de professores de língua portuguesa, mesmo daqueles com um pouco mais de experiência no magistério, que evocam a defesa "do bem do [português] que circula nas redes sociais", associado ao português prescrito na gramática normativa, o que demonstra que o debate sobre língua(gem) realizado fora dos muros da universidade, ainda quando feito por quem passou por seus bancos, não deixa de ser problemático. Confesso que quando escuto um cidadão pouco ou nada alfabetizado, ou um indivíduo, que, mesmo escolarizado, é leigo em questões de língua(gem), dizer que fulano ou sicrano não sabe "falar português" e que beltrano "fala errado" ou ainda algo do tipo "nunca intendi português", sinto-me compelido a compreender e aceitar, dado o desconhecimento, por parte desses indivíduos, do estudo científico da língua(gem) e a condição de distanciamento deles em relação às discussões sobre o fenômeno linguístico.

Causa certo incômodo, porém, quando certos colegas, especialmente professores de língua portuguesa (alguns deles até com um bom tempo de experiência em sala de aula), ao observarem um indivíduo falar ou escrever apresentando algum desvio em relação aos padrões gramaticais considerados corretos, expressarem que aquele indivíduo não "sabe português", "não sabe falar", "não sabe escrever". São posicionamentos que parecem querer atestar que determinado indivíduo não sabe a língua que utiliza para se comunicar ou que ele é incapaz de se expressar na sua própria língua.

Nesse sentido, faço os seguintes questionamentos: o que é, afinal, para esses profissionais do ensino, "saber português"? O que eles ensinam? Não é difícil imaginar que, em sala de aula, o discurso que eles revelam sobre a língua(gem) se afaste, em certa medida, das contribuições que os estudos linguísticos têm produzido seriamente nessas últimas décadas. É preocupante imaginar como se dá a prática de ensino de língua portuguesa desses profissionais, principalmente tendo em conta que o discurso diz bastante sobre o tipo de postura do professor, considerando, seguindo Geraldi (2006), que a concepção de linguagem que o professor de língua portuguesa assume orienta a sua metodologia de trabalho, sendo, portanto, determinante para sua prática pedagógica em sala de aula.

Pelo que se tem observado, o problema é que, tal como muitos sujeitos sem formação nessa especialidade, eles insistem em confundir, por exemplo, língua com gramática (como se 
só existisse um tipo de gramática), língua com norma padrão, "falar e escrever bem" com dominar com maestria regras gramaticais (da gramática normativa, claro, porque não se pode esquecer que há uma gramática descritiva e uma gramática internalizada, como bem teorizam linguistas como Possenti (1996) e Travaglia (1995), entre tantos outros). Não estou aqui advogando que a escola não possa trabalhar com a gramática normativa, porque entendo que é papel da escola ensinar a norma linguística prestigiada socialmente, mas sempre respeitando a diversidade linguística que toma conta da vida no espaço de sala de aula e nos demais espaços da vida social. A questão, a meu ver, é como se ensina a norma padrão e que lugar ela deve ocupar na sala de aula.

Esses profissionais (professores) parecem não saber que, quando se fala de língua(gem) e de regras gramaticais, trata-se de coisas bem distintas, como exemplarmente também ensina o escritor Luis Fernando Veríssimo (2002), em sua crônica $O$ gigolô das palavras, da qual reproduzo o trecho a seguir:

[...] a linguagem, qualquer linguagem, é um meio de comunicação e que deve ser julgada exclusivamente como tal. Respeitadas algumas regras básicas da Gramática, para evitar os vexames mais gritantes, as outras são dispensáveis. A sintaxe é uma questão de uso, não de princípios. Escrever bem é escrever claro, não necessariamente certo. Por exemplo: dizer "escrever claro" não é certo mas é claro, certo? O importante é comunicar. (E quando possível surpreender, iluminar, divertir, mover... Mas aí entramos na área do talento, que também não tem nada a ver com Gramática.) A Gramática é o esqueleto da língua. Só predomina nas línguas mortas, e aí é de interesse restrito a necrólogos e professores de Latim, gente em geral pouco comunicativa. Aquela sombria gravidade que a gente nota nas fotografias em grupo dos membros da Academia Brasileira de Letras é de reprovação pelo Português ainda estar vivo. Eles só estão esperando, fardados, que o Português morra para poderem carregar o caixão e escrever sua autópsia definitiva. É o esqueleto que nos traz de pé, certo, mas ele não informa nada, como a Gramática é a estrutura da língua mas sozinha não diz nada, não tem futuro. As múmias conversam entre si em Gramática pura.

Ele é um grande escritor e como tal lida com a palavra e tem intimidade com ela. Sabe se expressar com maestria. Sabe que o importante é comunicar (eu prefiro dizer interagir), que a gramática é “o esqueleto da língua” e que, por conseguinte, não é necessário saber todas as regras da gramática normativa para falar ou escrever bem". Afinal, como também ensina Monteiro Lobato (1962), por meio do diálogo entre Narizinho, Dona Benta e Pedrinho, em Fábulas, língua em uso e gramática normativa não se confundem:

Pilhei a senhora num erro!", gritou Narizinho. "A senhora disse: 'Deixe estar que já te curo!' Começou com o Você e acabou com o Tu, coisa que os gramáticos não admitem. O 'te' é do 'Tu', não é do 'Você'"...

"E como queria que eu dissesse, minha filha?"

"Para estar bem com a gramática, a senhora devia dizer: 'Deixa estar que já te curo'." 


\begin{abstract}
"Muito bem. Gramaticalmente é assim, mas na prática não é. Quando falamos naturalmente, o que nos sai da boca é ora o você, ora o tu; e as frases ficam muito mais jeitosinhas quando há essa combinação do você e do tu. Não acha?"

"Acho, sim, vovó, e é como falo. Mas a gramática..."

"A gramática, minha filha, é uma criada da língua e não uma dona. O dono da língua somos nós, o povo; e a gramática - o que tem a fazer é, humildemente, ir registrando o nosso modo de falar. Quem manda é o uso geral e não a gramática. Se todos nós começarmos a usar o tu e o você misturados, a gramática só tem uma coisa a fazer..." "Eu sei o que é que ela tem a fazer, vovó!", gritou Pedrinho. "É pôr o rabo entre as pernas e murchar as orelhas..."

Dona Benta aprovou.
\end{abstract}

Se insisto em problematizar essa questão é porque entendo que não só um estudioso da língua(gem) deve ter como ponto pacífico que uma dada língua não se reduz a regras gramaticais, sobretudo de uma gramática normativa, mas também todo e qualquer professor de língua portuguesa comprometido com um ensino produtivo e em consonância com o real funcionamento da lingua(gem). Entendo que quem ensina a língua (e aqui, no caso, a língua portuguesa) deve evitar esse tipo de obviedade, bem ilustrada na fala de Dona Benta, sob pena de estar contribuindo não só para a proliferação de atitudes preconceituosas contra determinados falantes/escreventes, como também para a interdição de determinados indivíduos, porque é disso que se trata, antes de tudo, quando se atesta a incompetência linguística de alguém.

É um tanto lamentável quando um profissional, de quem se espera preparo para ensinar a língua portuguesa, confunde língua em uso com regras da gramática normativa. Chega a ser lamentável ele achar que alguém que não se expressa "corretamente", conforme as regras da gramática normativa, não sabe a língua portuguesa. Porque, afinal, é estranho imaginar que alguém que nasce e cresce falando uma dada língua não saiba nela se expressar. Até mesmo esse profissional que se julga saber o português faz uso, em diversas situações, de determinadas construções linguísticas que se afastam da norma padrão. Ele mesmo deve trocar frequentemente o $\boldsymbol{t} \boldsymbol{u}$ e o você, exemplificados por Dona Benta, no recorte acima, nas situações comunicativas. Contudo, que fique claro, concordo com a posição, largamente difundida entre os linguistas, segundo a qual, em contextos formais de uso da língua, a obediência às regras gramaticais não é só uma questão opcional, mas um imperativo. Do contrário, pode-se ter a mesma "sorte" que um Aldevandro Cantagalo, personagem do conto O caçador de pronomes, de Monteiro Lobato (1956), cujo nascimento e falecimento são atribuídos, pelo narrador, a um erro de gramática, mais precisamente de escolha e colocação 
pronominal ${ }^{1}$. Insisto aqui, retomando Luis Fernando Veríssimo, "O importante é comunicar. (E quando possível surpreender, iluminar, divertir, mover...”).

Quando se diz que determinado indivíduo "não sabe português", isso não pode, portanto, ser confundido com o fato de ele não dominar as regras da gramática normativa. Além do mais, não quer dizer que ele não saiba a língua que usa e não domine as regras de funcionamento dessa língua. Que isso não faça pensar que ele não tenha uma gramática internalizada, aquele conjunto de regras que todo falante de uma língua domina e faz uso nas diversas situações de comunicação, da mais informal à menos informal, como afirma Possenti (1996). Na verdade, a asserção adequada (e que deve ser sempre demarcada, se a intenção é destacar, da fala/escrita de um indivíduo, a desobediência deste em relação à norma padrão) é que aquele indivíduo não sabe o português padrão.

Está claro, pois, para qualquer profissional minimamente sintonizado com as discussões de sua área, que o mais interessante é pensar o uso que o indivíduo faz da língua, conforme os diversos contextos da vida social, considerando que ele deve adequá-la a cada um desses contextos, utilizando, inclusive, se for o caso, o "português errado", se os demais indivíduos envolvidos na situação comunicativa tiverem, no seu dia-a-dia, comportamento linguístico nesse linguajar. Trata-se, assim, de uma forma de ser respeitoso com esse outro, de se dispor a falar e a escutar na língua desse outro, de não lhes negar o direito de se expressar no seu linguajar, de modo a não lhes interditar o seu dizer. E faz tempo, como se sabe, que renomados linguistas como Bagno (2002, 2003, 2006), Faraco (2001, 2007), Fiorin (2002), Oliveira (2007), Possenti (1996), e Scherre (2005) discutem esse conjunto de questões que atravessa o campo dos estudos da linguagem.

Com farta e rica produção que emana dos núcleos de pesquisa no país, o que se pode imaginar é que os discursos postos em questão aqui só podem ser resultado de compreensões distorcidas e/ou equivocadas sobre o fenômeno linguístico ou da pouca familiaridade com essa produção da linguística. Não se pode compactuar, portanto, com a ideia de que a representação social sobre a língua de um professor de língua portuguesa, como parece

\footnotetext{
${ }^{1}$ Para esclarecer melhor, cito aqui uma passagem que ilustra o fato que culmina com o nascimento de Aldevandro Cantagalo. O conto mostra que o pai de Aldevandro é obrigado a se casar com a filha mais velha (Maria do Carmo) do Coronel Triburtino, após aquele ter escrito uma carta para Laurinha (a filha mais nova do coronel, por quem o pai de Aldevandro sentia desejos), empregando, no texto da carta, para se referir à moça a quem escrevia, a construção linguística amo-lhe. Diante desse fato, o Coronel Triburtino assim sentencia o pai de Aldevandro: "Vassuncê mandou este bilhete à Laurinha dizendo que ama-'Ihe'. Se amasse a ela deveria dezer (sic) amo-'te'. Dizendo 'amo-lhe' declara que ama a uma terceira pessoa, a qual não pode ser senão a Maria do Carmo. Salvo se declara amor à minha mulher..." e completa: "Os pronomes, como sabe, são três: da primeira pessoa - quem fala, e neste caso vassuncê; da Segunda pessoa - a quem fala, e neste caso Laurinha; da terceira pessoa - de quem se fala, e neste caso do Carmo, minha mulher ou a preta. Escolha!”.
} 
transparecer em dizeres de certos professores, seja aquela do discurso do senso comum, especialmente quando se sabe hoje que, há quase duas décadas, os Parâmetros Curriculares Nacionais, principalmente aquele destinado ao ensino fundamental, apontam e direcionam o trabalho com a diversidade linguística em sala de aula de língua materna. Isso parece já ser uma razão bastante pertinente para suscitar um programa de formação consistente com esses profissionais que dê conta de abordar questões sobre língua(gem), variação, adequação linguística, noção de erro, tipos de gramática, ensino de língua... de modo a possibilitar a (re)construção de uma visão mais coerente sobre o fenômeno linguístico.

O desenvolvimento de um programa consistente e adequado às condições de trabalho do professor e a insistência na formação continuada desse profissional se apresentam como possibilidades de estabelecer uma ruptura com essas compreensões equivocadas que ainda pairam sobre as questões de linguagem nos diversos espaços sociais, inclusive na escola, já que, ao que parece, muitas das questões da investigação linguística, especialmente aquelas da Sociolinguistica com foco voltado para o ensino, não têm ainda se refletido plenamente na formação de alguns professores de língua portuguesa.

Encerro enfatizando que, para o professor de línguas, de língua portuguesa em especial, uma compreensão do fenômeno linguístico em sintonia com os pressupostos das ciências da linguagem, da Sociolinguística à Análise do discurso, não é só desejável, mas também uma obrigação, como condição de um ensino de língua responsável e comprometido em oferecer ao alunado uma formação coerente com o real funcionamento da língua(gem), com o seu uso pelos falantes/escreventes nas diversas situações de comunicação. É igualmente desejável, por fim, que os cursos superiores de formação de professores de língua portuguesa assumam também o compromisso de criar condições mais efetivas para que as contribuições dos estudos da linguagem sejam melhor assimilidas pelos futuros professores, no sentido de dotá-los das competências requeridas para o exercício de um ensino de língua materna produtivo.

\section{REFERÊNCIAS}

BAGNO, M. (2002). Preconceito lingüístico - o que é, como se faz. 15 ed. Loyola: São Paulo. Editorial.

(2003). A norma oculta: língua \& poder na sociedade brasileira. São Paulo: Parábola 

set./out.

(2006). Nada na língua é por acaso. Presença Pedagógica, v.12, n.71, p. 22-29,

BAKHTIN, M. (2003). Estética da criação verbal. Tradução do russo de Paulo Bezerra. 4. ed. São Paulo: Martins Fontes.

FARACO, C. A. (2001). Guerras em torno da língua: questões de política lingüística. In: FARACO, C. A. (Org.). Estrangeirismos: guerras em torno da língua. 2. ed. São Paulo: Parábola Editorial, p. 37- 83.

FARACO, C. A. (2007). Por uma pedagogia da variação lingüística. In: CORREA, D. A. (Org.). A relevância social da Lingüística: linguagem, teoria e ensino. São Paulo: Parábola Editorial, p. 21-50.

FIORIN, J. L. (2002). Os Aldevandros Cantagalos e o preconceito linguístico. In: SILVA, F. L. da e Moura, H. M. de M. $O$ direito à fala: a questão do preconceito linguístico. Florianópolis: Editora Insular, p. 23-37.

GERALDI, J. W. (2006). Concepções de linguagem e ensino de português. In: (Org.). O texto na sala de aula. São Paulo: Ática, p. 39-46.

LOBATO, M. (1956). O colocador de pronomes. In: . Negrinha. São Paulo: Brasiliense. - (1962). Obras completas de Monteiro Lobato: fábulas e histórias diversas. São Paulo: Brasiliense. (2002). Peter Pan. 32. ed. São Paulo: Brasiliense.

OLIVEIRA, G. M. de. (2007). A 'virada político-lingüística' e a relevância social da lingüística e dos linguistas. In: CORREA, D. A. (Org.). A relevância social da Lingüística: linguagem, teoria e ensino. São Paulo: Parábola Editorial, p. 79-93.

POSSENTI, Sírio. (1996). Por que (não) ensinar gramática na escola. Campinas, ALB. Mercado de Letras.

SCHERRE, M. M. P. (2005). Doa-se lindos filhotes de poodle: variação lingüística, mídia e preconceito. São Paulo: Parábola Editorial.

TRAVAGLIA, L. C. (1995). Gramática e interação: uma proposta para o ensino da gramática no $1^{\circ}$ e $2^{\circ}$ graus. 3. Ed. São Paulo: Cortez.

VERISSIMO, L. F. (2002). O gigolô das palavras. In: .O nariz e outras crônicas: Luis Fernando Veríssimo. 10. ed. v. 14. São Paulo: Ática, p. 77 - 78. Disponível em: < http://ensinomediodigital.fgv.br/disciplinas/portugues/curso1/aula3/artigos/o_gigolo_das_pala vras.pdf >. Acesso em 21 fev. 2014. 


\section{O AUTOR}

José Cezinaldo Rocha Bessa possui graduação em Letras/Língua Portuguesa e respectivas literaturas pela Universidade do Estado do Rio Grande do Norte (2005) e mestrado em Estudos da Linguagem, na área de concentração em Linguística Aplicada, pela Universidade Federal do Rio Grande do Norte (2007). Doutorando em Linguística e Língua Portuguesa pela Universidade Estadual Paulista Júlio de Mesquita Filho/FCLar, com período de estágio de doutorado no exterior na Université de Paris VIII (bolsa PDSE/CAPES), supervisionado pela Prof ${ }^{a}$ Marília Amorim. Atualmente é Professor Assistente III da Universidade do Estado do Rio Grande do Norte, no Campus de Pau dos Ferros. Bolsista do Conselho Nacional de Desenvolvimento Científico e Tecnológico (CNPq).

E-mail: cezinaldobessa@uern.br 